\title{
Brain death and organ donation in a neurosurgical unit: audit of recent practice
}

\author{
Douglas Gentleman, Janet Easton, Bryan Jennett
}

\begin{abstract}
Objective-To assess the potential for increasing the yield of donors by comparing the current pattern of brain death and organ donation in a neurosurgical unit with that reported in 1981 and with a recent national audit.

Design-Retrospective review of all deaths for 1986, 1987, and 1988 and prospective data for 1989.

Setting-A regional neurosurgical unit serving $2 \cdot 7$ million population

Results - Of 553 deaths, 35\% (191) patients died while on a ventilator and $17 \%(92)$ after discontinuation of ventilation. Medical contraindications to donation were found in $23 \%$ (32) of 141 patients tested for brain death, in $38 \%$ (19) of 50 patients who died while being ventilated who were not tested, and in $12 \%$ (11) of 92 patients no longer being ventilated. Consent for donation was sought in $88 \%$ (96) of 109 medically suitable brain dead patients and granted in $70 \%(67)$ of these. Half those with permission for multiorgan donation had only the kidneys removed.

Conclusions-More organs may be lost owing to transplant team logistics than by failure to seek consent from relatives of brain dead patients. The estimated size of the pool of potential donors depends on what types of patients might be considered. Ensuring that all who die while being ventilated are tested for brain death and considering the potential for donation before withdrawing ventilation could yield more donors. Ventilating more patients who are hopelessly brain damaged to secure more donors raises ethical and economic issues.
\end{abstract}

\section{Introduction}

In the United Kingdom more patients with renal failure are considered suitable for transplantation than in other countries, but there are fewer cadaver donors in Britain than in most European countries.' Views differ about the size of the pool of potential donors and about why only a proportion of possible donors eventually donate organs. There is therefore controversy about how best to increase the supply of kidneys and other solid organs.

In 1981 we reported 609 cases of brain death from this and two other British neurosurgical units, ${ }^{2}$ and we also reviewed 1228 brain dead renal donors from the records of the United Kingdom Transplant Service. ${ }^{3}$ By extrapolation we estimated that there are about 4000 cases of brain death in Britain each year. A prospective audit in England suggests, however, that at present only half this number occurs. ${ }^{4}$ Of the transplant service's donors in $1977-80,39 \%$ came from the $14 \%$ of hospitals that housed a neurosurgical unit ${ }^{3}$; in 1987 the service recorded that the $12 \%$ of these hospitals provided $46 \%$ of the kidneys donated. ${ }^{5}$ Head injuries accounted for the deaths of $55 \%$ of the donors in the three neurosurgical units ${ }^{2}$ and $50 \%$ of our national sample ${ }^{3}$ but less than $40 \%$ in the recent English audit. ${ }^{\circ}$

Neurosurgical practice clearly influences the supply of donors, and we considered it timely to review recent experience in our neurosurgical unit to discover the current pattern of brain death and of organ donation. We also assesed the potential for increasing the yield of donors.

\section{Patients and methods}

The Institute of Neurological Sciences in Glasgow serves a population of 2.7 million in the west of Scotland and includes a neurosurgical intensive care unit of eight beds. The regional renal transplant unit is three kilometres away, but the nearest units for heart, lung, and liver transplants are over $100 \mathrm{~km}$ distant.

We identified all deaths over four years (1986-9), noting whether they occurred on the ward or in the intensive care unit and whether during mechanical ventilation, after ventilation had been stopped, or in patients who had not been ventilated. For patients who died while being ventilated we noted how many were tested for brain death and in how many of these consent for donation was sought, how many became donors, and what organs were taken. The incidence of and reasons for medical unsuitability for organ donation in the different groups were noted. We estimated how many might have become donors among those untested who died while being ventilated and among those from whom ventilation had been withdrawn. The study was prospective for 1989 and retrospective for the previous three years.

\section{Results}

Of 553 deaths, 281 (51\%) were in the intensive care unit; 191 died while being ventilated $(35 \%$ of all deaths in the neurosurgical unit). Another 92 died during spontaneous breathing after ventilation had been stopped (17\% of all deaths); half of these occurred in the intensive care unit, the rest after return to a ward (table I). At some stage 283 of patients who died had been ventilated $(52 \%$ of all deaths and $84 \%$ of those in the intensive care unit). The number of patients who died while being ventilated ranged from 41 to 64 per

TABLE I - Deaths in a neurosurgical unit 1986-9

\begin{tabular}{lccr}
\hline & $\begin{array}{c}\text { In intensive care } \\
\text { unit }(\mathrm{n}=281)\end{array}$ & $\begin{array}{c}\text { In wards } \\
(\mathrm{n}=272)\end{array}$ & $\begin{array}{c}\text { Total } \\
(\mathrm{n}=553)\end{array}$ \\
\hline $\begin{array}{c}\text { No (\%) of patients: } \\
\text { Being ventilated }\end{array}$ & $191(68)$ & & \\
$\begin{array}{c}\text { After ventilation } \\
\text { stopped }\end{array}$ & $46(16)$ & $46(17)$ & $92(17)$ \\
Not ventilated & $44(16)$ & $226(83)$ & $270(48)$ \\
\hline
\end{tabular}

Correspondence to: Professor Jennett.

BrMed f 1990;301:1203-6 


\begin{tabular}{lc}
\hline Cause & No $\%)$ \\
\hline Head injury & $75(53)$ \\
Road accidents & $49(35)$ \\
Falls & $21(15)$ \\
Assaults & $3(2)$ \\
Other & $2(1)$ \\
Cerebrovascular & $43(30)$ \\
accident & \\
Hacmorrhages & $38(27)$ \\
Infarcts & $5(4)$ \\
Infection & $11(8)$ \\
Primary intracranial & $7(5)$ \\
neoplasms & $4(3)$ \\
Extracranial & \\
malignancy & \\
Hereditary enzyme & $1(1)$ \\
defect & \\
\hline
\end{tabular}

year. The standard British criteria and tests for brainstem death were applied to 141 of the 191 patients who died while being ventilated (74\%) and were fulfilled in every case. The cause of brain damage in brain dead patients was head injury in $75(53 \%)$, and a cerebrovascular accident in $43(30 \%)$ (table II). Of the 141 brain dead patients, $32(23 \%)$ were judged to be medically unsuitable for organ donation for various reasons (table III).

The relatives of 96 of the remaining $109(88 \%)$ patients had been asked to consent to donation, and 67 families agreed $(62 \%$ of all potential donors and $70 \%$ of those asked). Requests were made by neurosurgeons in 94 cases and by anaesthetists in two. Consultants made the requests in 38 cases, senior registrars in 45 , and registrars in 11 , with success rates of $67 \%, 72 \%$, and $67 \%$, respectively. The proportion of families who agreed to donation varied from $52 \%$ to $95 \%$ from year to year, for no apparent reason. The procurator fiscal refused permission for organs to be removed from two of the 67 patients. The 65 actual donors $(60 \%$ of the potential donors among the brain dead patients) accounted for $48 \%$ of all donors of solid organs in the west of Scotland during these four years - a similar proportion to the United Kingdom Transplant Service kidney donors from hospitals with a neurosurgical unit in 1987.

There were only nine possible potential donors among the 50 patients who had been ventilated until death but in whom tests for brain stem death had not been done. There were medical contraindications to donation in 19 (table III); asystole occurred within six hours of arrival in 12 and in theatre in four; in four others the preconditions for brain death were not satisfied; two had multiple factors. Over the four years 92 patients died after ventilation had been stopped, usually after a decision to limit treatment. There were medical contraindications to organ donation in 11 (table III), three had unexpected asystole, and the relatives of two had expressed a wish not to consider donation. Of the remaining 76 patients, $49 \%$ died within 24 hours of stopping ventilation but $15 \%$ survived more than a week.

\section{Discussion}

The debate about how most effectively to increase the supply of cadaver organs in Britain has so far focused on two questions: How many patients who die in hospital are potential donors because they are brain dead? and, Why do some brain dead patients not provide organs? Another point of inquiry - why more patients do not become potential donors-begs the question of how to define a potential donor. Should all who die while being ventilated be defined as potential donors or only those who have been formally tested for brain death? Or should the definition be limited to the smaller subset who are both brain dead and considered

TABLE III -Reason for patients being medically unsuitable for organ donation

\begin{tabular}{|c|c|c|c|c|}
\hline & \multicolumn{2}{|c|}{ Died while being ventilated } & \multirow[b]{2}{*}{$\begin{array}{l}\text { Ventilation stopped } \\
(\mathbf{n}=92)\end{array}$} & \multirow[b]{2}{*}{ Total $(\mathrm{n}=283)$} \\
\hline & $\begin{array}{l}\text { Tested for brain death } \\
\qquad n=141)\end{array}$ & $\begin{array}{l}\text { Not tested for brain } \\
\text { death }(n=50)\end{array}$ & & \\
\hline $\begin{array}{l}\text { No unsuitable because of: } \\
\text { Infection }\end{array}$ & 11 & \\
\hline $\begin{array}{l}\text { Hypotension with or } \\
\text { without anuria }\end{array}$ & 5 & 7 & & 12 \\
\hline Extracranial malignancy & 5 & 2 & 2 & 9 \\
\hline Diseased or damaged organs & 4 & 3 & & 7 \\
\hline Other diseases & 2 & & 3 & 5 \\
\hline Age & $2^{\star}$ & & $1 \dagger$ & 3 \\
\hline Multiple factors & 3 & & 1 & 4 \\
\hline Total (\%) unsuitable & $32(23)$ & $19(38)$ & $11(12)$ & $62(22)$ \\
\hline
\end{tabular}

*Infants.

† Aged 79 years to be medically suitable to donate organs? We have confirmed the finding of the recent English audit that substantial numbers of patients who die while being ventilated are not tested for brain death ${ }^{4}$ and have also defined a further group whose ventilation was stopped without their having become brain dead but who died soon afterwards. Another group of potential donors has recently attracted attention-those with overwhelming brain damage who are not ventilated but some of whom might have become brain dead if they had been ventilated. We consider these groups in turn.

\section{BRAIN DEAD PATIENTS}

Medical unsuitability to donate organs-This applied to $23 \%$ of 141 patients in Glasgow compared with $17 \%$ of 282 in the English audit. ${ }^{+}$In both series common reasons for unsuitability were infection and malignant or other advanced disease. There might have been fewer exclusions if transplant teams had been consulted more often; some patients believed by their doctors to be unsuitable as donors might have been accepted. In both these series, as well as in some other reports, many patients became unsuitable as donors because of hypotension, with or without anuria. It has been suggested that if potential donors were given more vigorous medical support fewer might become unsuitable for these reasons. ${ }^{7.9}$

Failure to ask or obtain permission from relativesTransplant surgeons often suggest these as important reasons for the low yield of donors, hence the proposals for required request or for opting out registers. However, the English survey and a recent report from Cambridge both showed a request rate of $96 \%,{ }^{410}$ and in Glasgow it was $88 \%$. Refusal rates in these three studies were $30 \%, 10 \%$, and $30 \%$, respectively; the lower rate in Cambridge was perhaps explained by its coming from a single hospital with an active transplant programme. We found no difference in success rates when requests were made by consultants, senior registrars, or registrars, but it has been suggested that using transplant coordinators or other identified trained staff might reduce the refusal rate. ${ }^{8}$ Many refusers probably represent the minority that every national opinion survey shows is unwilling to donate organs for transplantation. Consent may not depend as crucially as some believe on the commitment and persuasiveness of the person who asks permission.

Permission withheld by coroner-About half the cases of brain death in most series are head injuries, and these have to be reported to the coroner (procurator fiscal in Scotland). Of 109 medically suitable potential donors in Glasgow, only two were lost because of legal implications. In Cambridge the coroner withheld permission in eight of 40 cases - more potential donors than were lost from refusal by relatives, ${ }^{10}$ whereas the English audit did not mention this as a reason for losing donors. The Coroners' Society was represented in the discussions in the 1970s about criteria for brain death and the code of practice for organ donation. Each coroner (or procurator fiscal) has complete discretion about decisions in his jurisdiction, and in the early years of transplantation some coroners were more helpful than others. To discover such variations in practice 15 years later is disappointing; it leads to a significant loss of organs in some places.

Failure to use organs offered-Transplant surgeons complain about failure to obtain consent, but transplant teams sometimes fail to use offered organs. In Glasgow 16 of 24 consents in 1989 were for donation of multiple organs, but in only half of these were organs other than kidneys used. The reasons were either that hypotension had developed before the transplant team arrived or that resource constraints in recipient units led to offers being declined. In the English audit multiple organs 
were taken from 89 of 148 donors, but how many others had offered multiple organs was not stated. ${ }^{4}$ In four cases no organs were taken and overall two kidneys, 20 livers, and 22 lungs were not used. In the Cambridge series one pair of kidneys, three hearts, and a liver were not used because of lack of a suitable recipient; three livers were lost because of nursing shortages in the transplant intensive care unit. ${ }^{10}$ These losses were among 16 donors who offered multiple organs and occurred in spite of the close proximity of transplant surgeons using all these organs. The failure of transplant surgeons to take organs when consent had been obtained was noted by two other donor units. ${ }^{11}$ The ischaemia time is much shorter for other organs than for kidneys - four hours for hearts and lungs, 8-12 hours for livers. ${ }^{8}$ This, combined with the distance between many donor hospitals and the few centres transplanting these organs, is bound to cause problems. ${ }^{13}$

\section{VENTILATED PATIENTS NOT TESTED FOR BRAIN DEATH}

In both the English and Glasgow surveys 26\% of patients identified as possibly brain dead did not have formal tests of brain stem function. Gore et al emphasised that there were sometimes good reasons for not testing for brain death, ${ }^{414}$ but others have speculated that negative attitudes to transplantation and resource restraints in donor intensive care units might also contribute. ${ }^{8}$ In $38 \%$ of the 50 untested cases in Glasgow there were medical contraindications to donation, and in another $32 \%$ asystole occurred before testing was done. In a number of other reports asystole was given as a reason for not proceeding to donation, but in both the English and the Cambridge surveys kidneys were retrieved from a small number of patients who had become asystolic. Asystole may occur before testing for brain death because of delay in initiating these tests or because an interval of 12-24 hours was required between the first and second set of tests. Delay also increases the likelihood of hypotension, resulting in organs becoming unsuitable for donation. The British criteria emphasised the need to satisfy the preconditions before the first testing but did not specify a long interval before repeating the tests. ${ }^{15}{ }^{16} \mathrm{In}$ our unit it is unusual for more than an hour to elapse between the first and second testing.

\section{PATIENTS IN WHOM VENTILATION WAS STOPPED BEFORE} DEATH

A decision to limit treatment was recorded in the notes of about half of all patients who died in this unit in the past two years. One form of limiting treatment is to stop ventilation, and in the past four years this was done in almost twice as many patients as died while being ventilated without being tested for brain death. Only $12 \%$ of those from whom ventilation had been withdrawn had medical contraindications to donation. Several of the 37 suitable patients who died within 24 hours of ventilation being withdrawn might have become donors, as could some of the 28 who lived for up to seven days after artificial ventilation had been stopped. Prolonging their ventilation would, however, raise ethical and resource issues similar to those that arise in the next group of patients.

BRAIN DAMAGED PATIENTS WHO DIED WITHOUT BEING VENTILATED

Some of the patients who die without ever being ventilated are admitted to hospital soon after an acute brain insult, commonly a head injury or an intracranial haemorrhage. Others suffer an acute incident when already in hospital, such as a cardiac arrest or a recurrent subarachnoid haemorrhage or some other sudden relapse or deterioration. When it is evident that the prognosis is hopeless a decision is made not to start ventilation because it would be futile. Some anaesthetists and nurses are not prepared to ventilate such patients with the specific intention of providing donor organs, and this was the reaction of staff in our unit during recent discussions. One objection is reluctance to embark on a major intervention with no prospect of helping the patient; another is unwillingness to commit professional time and other intensive care resources in these circumstances.

In one district general hospital in England, however, a protocol has been developed for patients with cerebrovascular incidents who are transferred to the intensive care unit in order to provide organs. This applies only to patients already considered medically suitable as donors and whose relatives have agreed to donation and to supportive measures to facilitate this. ${ }^{7}$ In this one hospital over a period of 19 months eight patients were identified and 21 organs retrieved - as many donors again as had been secured each year over several preceding years from normal intensive care unit practice. An audit being completed in Wales that includes deaths outside intensive care units has also discovered many such potential donors. ${ }^{1}$

EFFECT ON DONOR SUPPLY OF POLICIES FOR TREATING ACUTE BRAIN DAMAGE

At present most donors are patients who die while being ventilated in intensive care units; about half come from neurosurgical units, and about half of all donors are head injured. As more hospitals acquire computed tomography scanners neurosurgeons are likely to develop stricter triage guidelines to exclude the transfer of hopeless cases to regional units. More patients with hopeless acute brain damage are therefore likely to remain in district general hospitals or other hospitals. Quite apart from triage for transfer, guidelines are being developed for the management of acutely brain damaged patients, including indications for mechanical ventilation. Even so, the proportion of patients who are ventilated varies considerably from place to place and from one consultant to another in the same unit. In a recent study of 965 severely head injured patients in four neurosurgical units in the United Kingdom the ventilation rate ranged from $50 \%$ to $82 \%$ (G Teasdale et al, report to Medical Research Council, 1989), and in some units fewer still are ventilated. Among general intensive care units the variation in the proportion of deaths that occur while patients are being ventilated is considerable. ${ }^{17}$

International comparisons of the number of donors per million population need to take account of variations in the incidence of fatal head injuries, the proportion of patients who die in hospital, and the proportion in hospital who are ventilated. For example, the head injury death rate per million population in most European countries, in North America, and in Australia is more than twice that in Britain. ${ }^{18}$ Moreover, the number of intensive care beds per million population in the United States is 10 times that in Britain, and there is a greater tendency to use technological interventions such as ventilation. The number of fatal head injuries per million population has, however, been slowly but steadily falling in several Western countries over the past 20 years and so has the incidence of ischaemic and haemorrhagic strokes (other than those due to ruptured aneurysm). It is therefore difficult to predict the size of the pool of potential donors because it can vary with time and place.

\section{Conclusions}

The absolute number of potential donors depends on many factors, in particular on the definition of a potential donor. The belief that the main reason for losing potential donors is the failure to ask relatives to 
consent is no longer sustainable. There may be scope for seeking more donors among patients who now die after ventilation has been stopped. More willingness to make use of donors who had become asystolic is likely to be practical only when the transplant team is located near the intensive care unit.

The potential for increasing the supply of donors by ventilating more of the hopelessly brain damaged patients is considerable. Major constraints are the willingness of doctors and nurses to ventilate patients solely to enable them to become donors and the adequacy of resources in donor intensive care units. Resources should also be reviewed in transplant units to ensure that as many of the offered organs as possible are used. Ongoing audit could show how hospitals ranked in their donation rates and how various transplant units rated in results of transplantation and in responding to offers by successfully retrieving organs.

1 Anonymous. Organ donors in UK. Getting the numbers right [Editorial]. Lancet 1990;335:80-2.

2 Jennett $\mathrm{B}$, Gleave J, Wilson P. Brain death in three neurosurgical units. BMf 1981;282:533-9.

3 Jennett $B$, Hessett $C$. Brain death in Britain as reflected in renal donors. $B M F$ 1981;283:359-68.
4 Gore SM, Hinds CJ, Rutherford AJ. Organ donation from intensive care units in England. BMf 1989;299:1193-7.

Jennett B, Gentleman D. Brain stem death and organ donation. $B M \mathcal{F}$ 1989;299:1398-9.

Gore SM, Holland AJ, Hinds CJ. Organs for transplantation. BMf 1990; 300:464.

7 Feest TG, Riad HN, Collins CH, et al. Protocol for increasing organ donation after cerebrovascular deaths in a district general hospital. Lancet 1990;335. $1133-5$.

8 Wallwork J. Organs for transplantation. Improvements needed in supply and use. BMF 1989;299:1291-2.

9 Odom NJ. Organation donation. I. Management of the multiorgan donor. BMF 1990;300:1571-3.

10 Bodenham A, Berridge JC, Park GR. Brain stem death and organ donation. BMF 1989;299:1009-10.

11 Chapman DH. Organs for transplantation. BMf 1989;299:1463-4

2 Lowry KG, Lavery GG. Brain stem death and organ donation. $B M \mathcal{J}$ 1989;299:1218.

13 Odom NJ. Organ donation. II. Logistical disincentives to organ donation. BMF 1990;300:1573-5.

14 Gore SM, Rutherford AJ, Hinds CJ. Organ donation from intensive care units. $B M \mathcal{F}$ 1989;299:1399.

15 Conference of Medical Royal Colleges and their Faculties in the UK. Diagnosis of brain death. BMF 1976;ii:1187-8.

16 Conference of Medical Royal Colleges and their Faculties in the UK. Diagnosis of death. BMJ 1979;i:322.

17 Payne JN, Bowns IR, Lyon C. Organs for transplantation. BMf 1989;299: 1463.

18 Jennett B, Frankowski R. The epidemiology of head injury. In: Vinken PH, Bruyn GW, eds. Handbook of clinical neurology. Vol 13 (57). Amsterdam Elsevier, 1990:1-16.

(Accepted 7 September 1990)

\section{Everyday Aids and Appliances}

\section{Aids for disabled drivers}

\section{Christian Murray-Leslie}

Disabled people may require driving aids to enable them to drive for the first time, to adjust to increasing disability (as with progressive disorders such as rheumatoid arthritis and multiple sclerosis), or to return to driving after a single disabling illness (such as a stroke, amputation, or injury to the spinal cord).

Assessment and advice-The disabled person should first obtain medical advice from their general practitioner or medical specialist. When applying for a driving licence for the first time the applicant will be asked questions on disabling conditions. If a person already has a driving licence and has subsequently developed a disability that might affect driving safety he or she is obliged by law to notify the medical branch of the Driver and Vehicle Licensing Centre at Swansea as soon as possible. If there is no bar to driving but there is uncertainty about the feasibility or safety of driving advice may be sought from any one of the 10 United Kingdom driving assessment centres (see appendix). The centres provide impartial and noncommercial advice based on the assessment of driving capabilities and need for aids. Assessments on a static test module are usually followed by a test drive in a suitably adapted vehicle on a private road.

Choice of vehicle - When choosing a motor vehicle a disabled person and his or her advisers need to consider several points: (a) How will I and my passenger (who may also be disabled) get in and out of the car? (b) Are there problems of wheelchair access and stowage? $(c)$ Would I like to drive from a wheelchair? (d) Is an automatic transmission necessary or desirable? and $(e)$ Is power assisted steering necessary or desirable?

Access-Cars with two rather than four side doors generally provide a much wider aperture and therefore better access for both the driver and front seat passenger. Some manufacturers supply a disabled driver's model of a standard two door saloon, which includes extended seat runners to allow greater retrac- tion of the front seat. Extended seat runners can be fitted to most cars from upwards of $£ 40$ depending upon the vehicle model. Advice on getting in and out of cars, including wheelchair transfers, hoisting, and stowage, is given in an excellent booklet published by the Department of Transport.

Driving from a wheelchair is achieved in two ways. Firstly, the disabled person in his or her wheelchair is hoisted into the empty seat well of the car, or, secondly, a specially adapted vehicle is used and the wheelchair and its occupant enters by a ramp at the rear or side of the vehicle, the seating having been removed. Secure anchorage of the wheelchair and the wearing of a seat belt securely attached to the vehicle frame to the test standards of the Department of Transport is essential.

Automatic or manual transmission-Some disabled drivers, for example those with hemiplegia or those without any use in their legs, such as paraplegics, will require vehicles with automatic transmission, and others, for example those with painful arthritic joints, may also benefit. Fortunately, many smaller vehicles now have automatic gearboxes. Currently 45 models of car under 1.61 engine size are available with automatic transmission.

Power assisted steering may be essential to people with neurological impairment of their arms and of considerable help to those with painful conditions of the arms and spine.

Swivel seats (fig 1)-Access to vehicles can be improved by converting the existing car seat so that it is capable of rotating in and out of the car or by removing the existing seat and installing a special swivel seat. The price of these seats and the cost of fitting ranges from about $£ 175$ to $£ 335$. The seat should be capable of being locked in the rotated out position and have a headrest. Ideally it should be capable of sliding backwards and forwards in addition to rotating and have a good seat back, which can be reclined. "Leather look" 